\title{
Control Design of Automatic Intelligent Car Washing Machine Based on PLC
}

\author{
JING Dongxu ${ }^{1, a}$ \\ ${ }^{1}$ Tongliao Vocational College, Tongliao, 028000, China. \\ ajdxtvc@163.com
}

\begin{abstract}
With the vigorous development of China's auto industry in recent years, car washing has become more and more important. In view of the high cost, low efficiency, low cleanliness, low automation and low water utilization rate of the current car wash industry, this paper designs a fully automatic car washing machine based on S7-200 SMART PLC control system, which is intelligently cleaned. The system can realize all-round high-efficiency cleaning of the vehicle, and the sewage treatment system can realize the recycling and reuse of the car wash water. The system not only improves the efficiency, cleanliness and water resource utilization of the car wash, but also has the advantages of stable system, convenient use and simple maintenance, and has broad market prospect.
\end{abstract}

Keywords: PLC, Automatic Intelligent Car Washing, Style

\section{INTRODUCTION}

With the continuous development of economy and society, China's automobile industry is prospering day by day, and the number of private cars and buses is increasing. [1] The automobile industry is increasingly valued by the state and society. New energy vehicles are booming under the government's push [2], and the automotive service industry is welcoming an opportunity for vigorous development, among them, the most basic and critical car cleaning has been paid more and more attention by the public. People's requirements for car cleaning efficiency and quality are also increasing [3].

However, compared with many developed countries, many of China's car wash services still remain in the traditional manual cleaning or use of high-pressure water guns, and there is no reasonable control over the sewage discharge during the car wash process. And facing the problems of low efficiency, high energy consumption, low cleanliness, low automation, and easy damage to the body [4], it also violates the national sustainable development and energy-saving emission reduction development strategy [5]. Many foreign car washing machines are expensive and self-made car washing machines are often shoddy. Therefore, the development and popularization of automatic car washing machines suitable for China's car washing market is of great significance to China's economic development and environmental protection cause [6-7].
Therefore, in view of the drawbacks of the existing automatic car wash equipment [8-10], from the perspective of water saving and intelligent control, this paper developed an automatic car wash control system with programmable controller (PLC) as the core.This system not only includes good human-computer interaction and control interface, but also introduces sewage treatment and purification module, which realizes intelligent control and water circulation of the car wash process. The control system is stable and easy to maintain, easy to produce and promote, and has broad market prospects.

\section{CONTROL SYSTEM DESIGN}

The washing machine control system used by the predecessors and other countries uses the S5 series or S7-300 system PLC. However, this system requires a lot of cable connections, which is bulky and costly, and requires a large amount of pumping and discharging. The human lab or requires frequent opening and closing of the valve in the middle. The operation time is too long and the human resources will be wasted a lot. Therefore, we propose a control system composed of S7-200PLC SMART through the connector of SINEC L1 network. And add 1 solenoid valve ( 2 in total) to the original two venting valves, and add 4 solenoid valves to the drainage system of the two sewage tanks respectively, and the 10 solenoid 
valves are S7-200PLC SMART Control system to the extent of design,Sewerage purification control systems have been established to achieve the purpose of automatic extraction and purification of sewage. The structure of the control system is shown in Figure 1.

The operation panel has function buttons of the washing machine, and the detection signals include position detection of various nozzles, position detection of the blowing device, position detection of the body of the washing machine, detection of the defect position of each motor, position detection of the body of the washing machine, and each Motor defect and overload detection. This detection signal is connected to the input of the S7-200 SMART as the opening point of the detection device. If there is a problem in the working part, the fault point can be found according to the status of the various indicators on the input of the S7-200 SMART, which is very beneficial for the later maintenance and repair work. The output load of the PLC includes a motor-controlled AC contactor, a DC solenoid valve that controls the vehicle and the water supply, a light-emitting diode that is indicated by the panel, and a buzzer alarm for the fault reminder.

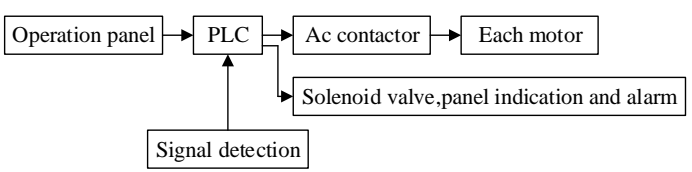

Figure 1 Control system structure

\section{INTELLIGENT CAR WASH SYSTEM HARDWARE DESIGN}

\subsection{PLC selection}

When considering the PLC selection and scheme, after comprehensively analysing the process and storage requirements, storage capacity, input and output requirements and costs, the system uses two S7-200PLC networked distributed control system solutions, one of which is a PLC host. It is located in the control room, which is convenient for users to control the various systems that operate the car wash process. Another PLC is placed in the washing shop as a slave station to control the input and output of the equipment in the washing workshop. The two PLCs use the switch connection to realize information interaction and coordination. control. This not only satisfies the performance requirements of the automatic car wash system, but also greatly reduces the overhead for the hardware system, and also reduces the number of cable connections and the size of the system, and improves the stability of the system.

The PLC selected by this control system is the S7-200 SMART series designed by Siemens for our customers. It has the following advantages: (1) The high-speed chip guarantees excellent performance, and its high-speed processing chip can realize the basic instruction execution time of 0.15 us. Leading to the same level of small PLC; (2) has a strong scalability, you can use the network cable to download the program to the plc without a dedicated programming cable, through the Ethernet interface can also communicate with other modules; (3) can be free Quickly realize the functions of equipment speed regulation and positioning. The integrated high-speed pulse output can make the frequency up to $100 \mathrm{kHz}$, and there are PWM/PTO output modes and different motion modes for users to choose; (4) Flexible and powerful communication Function, support PPI, MPI, As-I and other interface protocol communication, convenient for users to choose and configure according to actual needs; (5) Specially developed STEP 7-Micro/WIN SMAR T programming software has a good full mobile interface New code comments, password protection and other functions provide users with friendly and user-friendly design and efficient development efficiency.

\subsection{Control system hardware wiring}

The intelligent car wash system realizes communication between two PLCs and other modules such as a host computer through a switch.In order to ensure the accuracy and stability of the sliding guide, two sets of sliding guides and stepping motors are adopted to form the $\mathrm{X}$-axis. The $\mathrm{Y}$-axis and the Z-axis each have a set of sliding guides and a stepping motor. The nozzle bracket is mounted on the sliding guide of the Z-axis, and the structure of the three-dimensional motion system is shown in Figure 2.The system uses the SMART 700I IE touch screen as a human-machine interface to adjust the parameters of the car wash process, and controls the movement of the stepper motor by controlling the drive of the stepper motor. The specific hardware wiring diagram is shown in Figure 3.

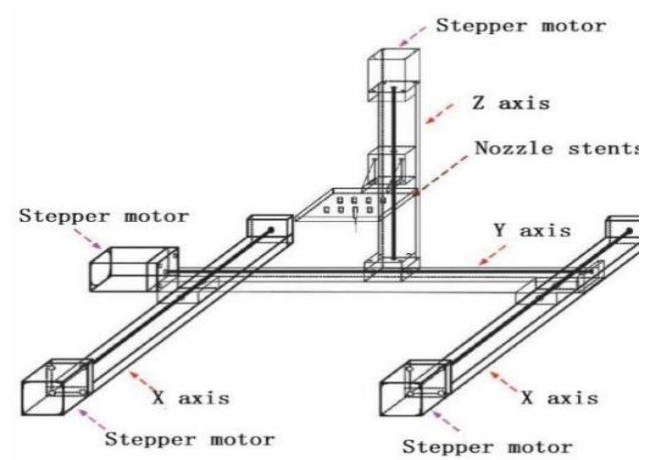

Figure 2 Schematic diagram of the three dimensional motion system 


\subsection{Sewage treatment purification system}

With the increasing use of automobiles, the water consumption for car washing is also increasing day by day. Therefore, the recycling and reuse equipment of car wash sewage is of vital significance for saving water and reducing water consumption [11].Considering car wash sewage, it mainly contains pollutants such as sediment, oil, and soluble organic matter. The sewage treatment of this system is based on ultrafiltration, which mainly includes multi-stage sedimentation, oil separation, four-stage filtration and separation, etc. Quartz sand, activated carbon and precision filtration and ultrafiltration, The technical flow chart is shown in Figure 3. After adding the circulating water equipment, the water consumption of the car wash system is reduced to less than $20 \%$, and the sewage recovery rate is over $80 \%$. The water quality of the reclaimed water basically meets the industrial water requirements.

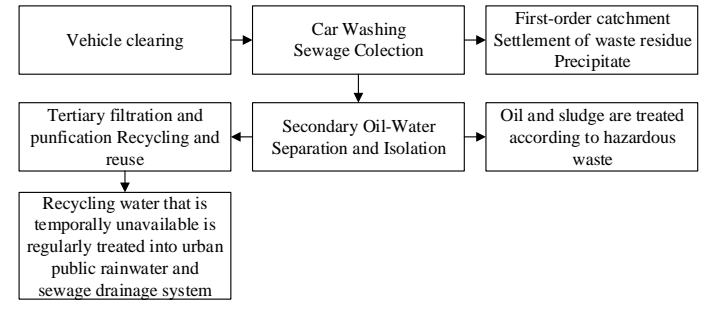

Figure 3 Car wash sewage reuse process

\section{SOFTWARE DESIGN OF CONTROL SYSTEM}

The car wash mode of this intelligent car wash system is divided into automatic mode and manual mode. The automatic mode is the main working mode, and the manual mode is mainly used for debugging and maintenance of equipment. Each car wash mode is modularly programmed for later maintenance and upgrades. The control requirements are: opening the entrance machine at the beginning to slow the vehicle into the washing shop. Open the bottom spray system to clean the wheel and the bottom of the vehicle during the vehicle's entry, and close the bottom spray system after the vehicle has completely crossed the bottom spray system. At the same time, the sensor is used to collect the vehicle parameters and the vehicle abnormality detection. After the detection is correct, the user is prompted to select the automatic car wash mode. During the car wash, the user can observe whether the washing, foam, water wax and air drying are completed through the touch screen, so that the vehicle time is completed. Knowing the current process, the user can also pause or cancel the process under abnormal conditions. When the car wash is finished, the system will remind the user to complete the car wash through the display and voice. After the vehicle leaves the washing workshop, the car wash sewage recovery and purification system will be started to realize the reuse of water resources, and finally the system will be shut down. The process flow of its specific work is shown in Figure 4.

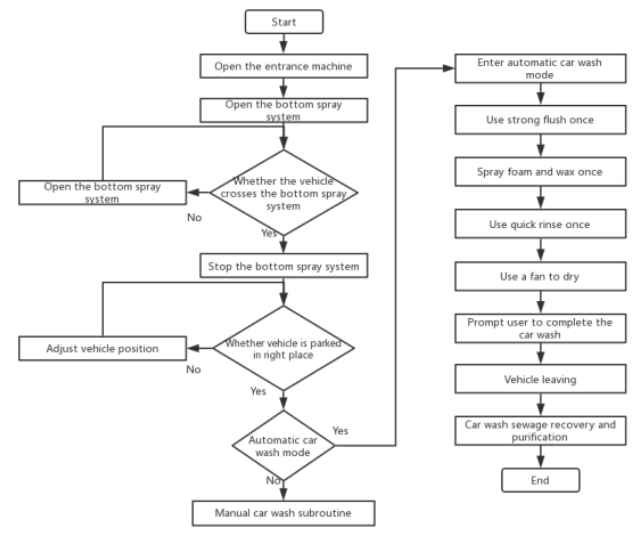

Figure 4 Car wash work flow chart

\section{CONCLUSION}

With the gradual development of intelligence and automation, the car wash service industry is also welcoming the ups and downs. The drawbacks of high cost, low efficiency, poor effect, low automation and serious waste of water for traditional manual and high pressure spray guns, At the same time, facing the contradiction between the vigorous development of China's new energy automobile industry and the high price of foreign brand car washing machines and the shoddy manufacture of self-made car washing machines, it is of vital importance to develop a smart car washing machine that meets the current situation of China's car washing industry. In view of the shortcomings of the existing intelligent car wash equipment, this paper designs a set of intelligent car wash system with PLC as the control centre, which can spray the entire cover of the vehicle bottom, wheel and roof to achieve the goal of efficient car wash. The sewage treatment system can achieve the effect of recycling the car wash sewage. While improving the utilization rate of water resources, it also reduces the amount of water used and the amount of pollution, and achieves the goal of environmentally friendly car wash. The system has a series of advantages such as high car wash efficiency, good effect, energy saving and environmental protection, simple operation and safety and stability, which has far-reaching significance for the development of China's car wash service industry. 


\section{REFERENCES}

[1] Zhang Binghui, Lv Yabo. Research on the Improvement of my country's Auto Industry Development Ability under the New Normal Economic Condition[J]. Economic Aspects, 2017(02):94-98.

[2] Chen Liuqin. Policy support for the development of new energy automobile industry[J]. Journal of Gansu Institute of Public Administration,2010, 25(3):15-24.

[3] Li Yanping. Analysis on the importance of cleaning in auto repair and the use of cleaning agents[J]. Technological Innovation and Application, 2015(5):79-79.

[4] Wang Lanqing, Zhang Xi, Li Yaru, et al. Status Quo of Car Washing Industry and Water Saving Measures[J]. Private Technology, 2018, No.220(7):166.

[5] State Council. "Thirteenth Five-Year" Comprehensive Work Plan for Energy Conservation and Emission Reduction[J]. China Building Materials, 2017, 15(3):10-10.

[6] Zhang Yuanwang. The status quo of the development of automobile washing machines at home and abroad[J]. Technology and Enterprise,2015(21):174-174.

[7] Na seong ki. Auto car washer for vehicle and car washing method therefor[p]. KR100732996B1,2007-06-21

[8] Huang Junyou. Design of Vehicle Washing System Based on PLC and Configuration[J]. Automation Technology and Application, 2014(4).

[9] Wang Huiying. Application of PLC in Automatic Car Washing Control System[J]. Mechanical \& Electrical Engineering, 2009, 26(3):108-110.

[10] Gaikwad R, Kharat S M M, Thakur J. PLC based automatic car washing system using proximity sensors[C]//2017 IEEE International Conference on Power, Control, Signals and Instrumentation Engineering (ICPCSI). IEEE, 2017: 1875-1878.

[11] P. Xu, Research and application of near-infrared spectroscopy in rapid detection of water pollution, Desalination and Water Treatment, 122(2018)1-4.
[12] P. Xu; N. Na; S. Gao; C. Geng, Determination of sodium alginate in algae by near-infrared spectroscopy, Desalination and Water Treatment, 168(2019)117-122.

[13] P. Xu, N. Na, A. M. Mohamad, Investigation the application of pristine graphdiyne (GDY) and boron-doped graphdiyne (BGDY) as an electronic sensor for detection of anticancer drug, Computational and Theoretical Chemistry, 1190(2020): 112996.

[14] Zhassandykyzy M, Aripovich T A, Wójcik $\mathrm{W}$, et al. Water recycling automation of car wash with cleaning channel and changeable adsorptive plate holders[J]. Przegląd Elektrotechniczny, 2017, 93(5): 144--147. 